\title{
ESCOLA INTEGRAL DE TEMPO INTEGRAL NO ESTADO DE MATO GROSSO DO SUL: REFLEXÕES SOBRE SUA CONSTITUIÇÃO E OS DESAFIOS DA POLÍTICA EDUCACIONAL
}

\author{
ESCUELA INTEGRAL A TIEMPO COMPLETO EN EL ESTADO DE MATO GROSSO \\ DO SUL: REFLEXIONES SOBRE SU CONSTITUCIÓN Y LOS DESAFÍOS DE LA \\ POLÍTICA EDUCATIVA
}

\section{INTEGRAL SCHOOL OF FULL TIME SCHOOL IN THE STATE OF MATO GROSSO DO SUL: THOUGHTS ON ITS CONSTITUTION THE CHALLENGES OF EDUCATIONAL POLITICS}

\author{
Reginaldo PEIXOTO ${ }^{1}$ \\ Olinda Rodrigues MAGALHÃES ${ }^{2}$
}

RESUMO: O objetivo desse artigo é o de refletir sobre as concepções de educação integral em período integral e sobre as políticas de implantação da escola em tempo integral no Estado de Mato Grosso do Sul. Assim, por meio de uma pesquisa bibliográfica e documental discutimos algumas legislações nacionais e estaduais que versam sobre a função o papel que a escola integral de tempo integral exerce na sociedade contemporânea. No Estado de Mato Grosso do Sul, foi adotada a pedagogia da autoria que coloca o aluno como protagonista, autor do processo de ensino e aprendizagem e desenvolvimento escolar que, na perspectiva da política educacional estadual, pode ser uma estratégia para formar um sujeito mais ético, crítico e conhecedor do seu papel social.

PALAVRAS-CHAVE: Educação integral. Escola de tempo integral. Currículo integrado. Escola de autoria.

RESUMEM: El propósito de este artículo es reflejar sobre los conceptos de educación integral a tiempo completo y sobre las políticas para implementar una escuela de tiempo completo en el estado de Mato Grosso do Sul. Entonces a través de una investigación bibliográfica y documental, discutimos algunas leyes nacionales y estatales que abordan el papel que desempeña la escuela a tiempo completo en la sociedad contemporánea. En el estado de Mato Grosso do Sul, se adoptó la pedagogía de la autoría, que coloca al estudiante como protagonista, el autor en el proceso de enseñanza y aprendizaje y desarrollo escolar, que, en la perspectiva de la política educativa, puede ser una estrategia para formar un sujeto más ético, crítico y consciente de su rol social.

PALABRAS CLAVE: Educación integral. Escuela a tiempo completo. Plan de estudios integrado. Escuela de autoría.

\footnotetext{
${ }^{1}$ Universidade Estadual de Mato Grosso do Sul (UEMS), Dourados - MS - Brasil. Professor Adjunto Efetivo do curso de Pedagogia e Professor do Programa de Mestrado em Educação. Doutorado em Educação, Arte e História da Cultura (UPM). ORCID: https://orcid.org/0000-0001-7452-7962. E-mail: regi.peixoto77@ gmail.com

${ }^{2}$ Universidade Estadual de Mato Grosso do Sul (UEMS), Dourados - MS - Brasil. Discente do Programa de PósGraduação. ORCID: https://orcid.org/0000-0001-7235-0526. E-mail: olindamagalhaes634@gmail.com
} 
ABSTRACT: The aim of this article is to ponder at the conceptions of all day full time education and implementation politics of a full time school in the state of Mato Grosso do Sul. Thus, through a bibliographic and documental research, it was discussed national and state legislations that argue about the function and the role of all day full time schools play on our contemporary society. In the State of Mato Grosso do Sul, the authorship pedagogy was adopted at schools and it sets the students as protagonists, authors of the teaching and learning process and school development which, upon the light of the state educational politics. Authorship pedagogy presents itself as a strategy to develop a more ethical, critical student and make them aware of their role in society.

KEYWORDS: Integral education. Full time school. Integrated curriculum. Authorship school.

\section{Introdução}

Historicamente, a função social da escola pública tem sido a de formar sujeitos críticos, que sejam capazes de buscar sua autonomia e, apesar do controle que meio social apregoa, a liberdade é um fator fundamental para as vivências e as relações sociais. Existe uma liberdade amparada em regras de convivências e papéis que cada um deve seguir, determinados pela cultura do seu povo, da sua região e do seu país.

Dessa forma, a formação integral dos estudantes tanto na dimensão quantitativa (mais tempo na escola) quanto na dimensão qualitativa (formação integral do ser humano), passa pelo papel que a escola exerce na vida dos sujeitos, pelas políticas públicas que amparam o ensino escolar e determinam quais ações pedagógicas são fortalecidas em níveis de currículo escolar, para cumprir o que se pretende - nesse caso, um sujeito integral, em aspectos que sobressaem aos conteúdos escolarizados como tradicionais.

A escola integral de tempo integral, além da ressignificação de conceitos das áreas de conhecimento, visa também a promover a integração curricular às vivências e necessidades dos sujeitos escolares e, no caso dessa política no Estado de Mato Grosso do Sul, o foco do ensino está na Autoria e no Protagonismo juvenil, ou seja, o educando é sujeito dos processos escolares, participante ativo do ensino e também da aprendizagem.

Ao buscarmos compreender melhor a diferença entre ensino integral e ensino de tempo integral, percebemos que o primeiro tem a ver com a formação ampla do sujeito, enquanto o segundo além da formação para a vida e as relações sociais, amplia o tempo do aluno na instituições escolares e a educação é ministrada com base num currículo que, além da Base Nacional Comum Curricular, insere outros componentes como parte diversificada, por isso a jornada escola se estende entre os turnos matutino e vespertino, geralmente. 
Dessa forma, para discutir o assunto elencado, a pesquisa é de caráter tanto bibliográfica como documental, pois expressa conceitos históricos e a legislação que ampara o ensino integral de tempo integral tanto no Brasil, como no Estado de Mato Grosso do Sul.

Com o intuito de melhor entendermos as questões que pertencem à temática aqui proposta como discussão, o artigo se divide em quatro momentos que, embora distintos, ao mesmo tempo complementares a saber: no primeiro momento tecemos uma breve discussão sobre a escola pública e a busca pela formação integral do estudante onde a premissa é reconhece-lo como um todo e não um ser fragmentado, ou seja, independentemente de a escola ser em tempo estendido ou regular, o sujeito precisa de uma formação integral a saber; no segundo procura-se destacar a educação Integral e a escola de tempo integral com suas relações e diferenças; no terceiro momento apresenta-se a educação integral na perspectiva da política educacional brasileira e sua implantação em Mato Grosso do Sul, cujo aporte pedagógico é conhecido como Pedagogia da Autoria e; no quarto momento, apresentamos de forma sintetizada a escola integral em período integral no estado de Mato Grosso do Sul: a escola de Autoria, uma política nacional de educação que visa superar modelos já implantados no Brasil na História da educação.

Assim, pretendemos concluir que o ensino integral tem a função de emancipar o sujeito e torna-lo mais participativo e que, somado ao tempo integral, o aluno pode ser protagonista da aprendizagem, transformador das suas vivências, pois se torna mais crítico, humano e emancipado. Embora isso exija investimentos públicos.

\section{A educação brasileira e a busca pela formação integral do sujeito escolar}

A escola pública na atualidade possui dentre outros papéis, o de formar sujeitos autônomos, críticos, e participantes da vida social. A escola na contemporaneidade, dentre outros papéis que possui como promover a aprendizagem do conhecimento universal, científico e sistematizado, tem também a premissa de preparar o sujeito para o trabalho e para as boas relações sociais.

$\mathrm{Na}$ atualidade, prima pela emancipação do sujeito escolar, ainda que o atual sistema econômico tenha sido um tanto quanto controlador. Apesar de sujeitos controlados que somos, a educação pode contribuir para uma sociedade mais justa, igualitária e solidária. Embora, com o passar dos tempos, a escola foi sofrendo o que Nóvoa (2007) chama de "transbordamento", ou seja, seu papel é muitas vezes confundido e ela assume funções que se distanciam do papel formativo. 
Nesse sentido, ainda que os papéis da escola muitas vezes tenham sido confundidos, temos que primar por uma formação de sujeitos livres, por isso, precisa haver uma parceria entre os professores para buscar a aprendizagem na sua totalidade e ter como maior desafio a pedagogia da presença para estreitar o relacionamento entre professor/aluno.

Para Mosé (2013) o modelo de escola que vislumbramos hoje é o de escola tradicional onde os alunos são passivos e só o professor é dono do saber, as aulas são fragmentadas e com tempo determinado para iniciar e terminar, parte dos alunos são desmotivados, as disciplinas também sofrem um isolamento em seu interior, os alunos pensam que estudam para os professores, para os pais e não para si e para a vida. Tal modelo ainda segue os preceitos da escola pós Segunda Guerra Mundial, reforçado durante a ditadura Militar Brasileira - trata-se de uma escola com pensamento tradicional que não responde às expectativas de jovens que vivem no contexto das tecnologias.

A escola que vislumbramos, ainda no Século XXI, segue combatendo toda a forma de pensamento crítico, eliminando a filosofia e esvaziando as disciplinas que permaneceram no currículo de seu caráter reflexivo e crítico. A escola se tornou um espaço longe dos desafios contemporâneos da sociedade. Os saberes são fragmentados, isolados, sem conexão com a realidade. A nossa escola é herdeira direta da sociedade industrial fragmentada, conteudista (MOSÉ, 2013).

Essa dificuldade de a escola encontrar o caminho para a valorização do sujeito e a transformação da sociedade, também é observada por Nóvoa (2007, p. 14) quando apregoa que, ainda na escola do século XXI,

[...] as crianças aprendem pouco, a estudar e a trabalhar. É um problema que se pode verificar nos países do sul da Europa, nas escolas portuguesas, italianas, gregas, em parte das francesas, e também nos países da América do Sul, diferentemente do que se vê nos países do norte da Europa, cujas escolas estão bastante focadas na aprendizagem do estudo, do trabalho, do trabalho autônomo, em grupo, no trabalho cooperativo. É central dispormos dessas ferramentas, principalmente quando se discute a importância da aprendizagem por toda a vida.

Nas palavras do autor, em alguns países, como aqueles do norte da Europa, a educação tem procurado a sua transformação, assim como a do sujeito humano, numa perspectiva da transformação do sujeito histórico. Já outros países continuam "capengando" ao promover um ensino que não dialogue com a realidade do seu público.

A escola brasileira historicamente não vem cumprindo com os preceitos de uma educação emancipatória e, no entanto, nos parece que o que se espera dela passa pela 
oportunidade de um desenvolvimento integral (cognitivo, ético, social e afetivo). Essa seria a educação integral que poderia ser ofertada em todas as escolas independente da sua jornada se dar em tempo regular ou integral. O estudante sempre foi e deverá ser reconhecido como um todo e não um ser fragmentado. Por tudo isso, as políticas educacionais vêm acenando com a necessidade de um ensino integral ser compreendido em todas as suas dimensões e desenvolver nesses estudantes habilidades, competências, hábitos e valores necessários para sua formação.

\section{A Educação Integral e a escola de tempo integral: relações e diferenças}

As diferenças entre escola de tempo estendido e escola de ensino integral são bem distintas, apesar de serem confundidas há uma diferença entre a educação integral (o currículo integrado) e a educação em tempo integral (a oferta ampliada do tempo escolar). Ao compreendermos a natureza coletiva do trabalho escolar que segundo Nóvoa (2007) envolve sujeitos internos e externos à escola, como um processo democrático, podemos analisar as relações que precisam ser consideradas em uma escola de educação integral e tempo integral: a comunidade interna e externa precisa conhecer de forma ampla como se dá o processo educativo em suas dimensões administrativas, financeira, pedagógica e infraestrutura. Todos esses processos estão presentes nas instituições escolares, mas precisam de um entendimento de todos os envolvidos. Eles permitem detectar os problemas, traçar metas, objetivos, estratégias com a participação de todos, com o foco na melhoria da qualidade de ensino.

Para Maurício (2009, p. 26),

A concepção de educação integral com a qual partilhamos, que embasa a proposta de extensão do tempo escolar diário, reconhece a pessoa como um todo e não como um ser fragmentado, por exemplo, entre corpo e intelecto. Entende que esta integralidade se constrói através de linguagens diversas, em variadas atividades e circunstâncias. A criança desenvolve seus aspectos afetivo, cognitivo, físico, social e outros conjuntamente.

A escola, nesse sentido, poderá potencializar e desenvolver atividades necessárias para que os estudantes possam atingir seus objetivos e construir seu projeto de vida. Essa concepção de educação coloca o estudante no centro do processo educativo. Educação integral não pode ser confundida com escola de tempo integral - a primeira diz respeito à integralização de um currículo que presume o ensino numa expectativa da formação total do sujeito, enquanto a segunda diz respeito ao tempo escolar ampliado para além de um turno de aula, conforme sustenta Moll (2009, p. 18): 
[...] de nada adiantará esticar a corda do tempo: ela não redimensionará, obrigatoriamente, esse espaço. E é, nesse contexto, que a educação integral emerge como uma perspectiva capaz de ressignificar os tempos e os espaços escolares.

Na crítica que faz a autora do excerto, necessitamos a criação de uma política de currículo integrado que possa atender a educação integral, considerando todos os espaços como locais de aprendizagem como parte da aprendizagem do aluno. A superação da fragmentação das disciplinas, o conteudismo, a falta de conexão com a realidade, todos esses problemas enfrentados no "chão" da escola impedem que o estudante tenha uma formação integral. Esses são problemas enfrentados tanto em escolas de tempo regular, quanto nas escolas de tempo integral (aquelas com ampliação da jornada escolar).

No referencial curricular de Mato Grosso do Sul está firmado que:

[...] escolas de tempo regular e em tempo integral devem possuir o mesmo princípio: oferecer ao seu público a oportunidade de se desenvolver de maneira plena no exercício de suas mais diversas atividades individuais e sociais (MATO GROSSO DO SUL, 2019, p. 51).

Esse princípio do qual trata a política educacional no Estado de Mato Grosso do Sul é primordial para que o estudante atue como protagonista, pesquisador e autor, construindo conhecimentos por meio do desenvolvimento das habilidades e competências prescritas nos currículos da educação básica.

As diferenças entre as escolas de tempo regular e tempo integral, podem ser observadas através de relatos de professores dos professores das escolas de Campo Grande - MS que aderiram ao projeto da escola de tempo integral denominada escola da Autoria, que enfatizam: a pedagogia da presença, as vantagens de conhecer melhor o estudante, maior tempo para pesquisa, estudo e elaboração de ferramentas necessárias para trabalhar com os estudantes, qualidade de vida (o docente lotado somente em uma escola), o docente orienta, acompanha e tutora esse estudante, o vínculo com a família e alunos é maior e o respeito às diferenças é bastante visível.

Conforme Alves (2011), a Educação Integral surge para uma reinvenção da prática educativa, tendo uma maior reflexão da realidade e as interações educacionais, por isso o fazer pedagógico se relaciona às vivências dos educandos. A educação serve como um processo de reflexão do papel do sujeito humano e vislumbra a transformação social, conforme assevera:

A escola de tempo integral surge com a proposta de resgatar muitas reflexões já existentes na educação. Para os que defendem a ampliação da jornada escolar, a reinvenção da prática educativa, ganha na proposta da escola 
integral um canal a mais de reflexão e ação rumo a uma realidade dinâmica, viva, de interação entre aprendizagens diversas, abandonando o isolamento teórico e consequentemente, prático a que estamos acostumados experimentar nos últimos anos (ALVES, 2011, p. 14).

Para a autora da citação, a prática educativa ganha uma nova oportunidade de ação entre o ensino/aprendizagem dos alunos, deixando o ensino mais dinâmico e tendo uma maior interação com a teoria e prática. A grande diferença na educação integral é a participação da família que precisa com base em um diagnóstico que revele quais são as maiores fragilidades dos estudantes no momento e, de que forma, escola e a família juntas podem apoiar esse estudante, deixando claro que se trata de uma parceria em que ambos assumem responsabilidades frente às situações observadas.

\section{A educação integral na perspectiva da política educacional brasileira e sua implantação em Mato Grosso do Sul}

Fank e Hutner (2013) em estudo realizado recentemente, discutem sobre a história das políticas educacionais no Brasil, mais acentuadas nas décadas de 1980 a 1990, as autoras apresentam programas e projetos com tempos estendidos os quais se configuram em grande parte como assistencialismo, essas ações governamentais, principalmente, são vistas como uma possibilidade de tirar jovens e crianças das ruas e, no entanto, a educação emancipadora, transformadora, é colocada em um segundo plano.

$\mathrm{Na}$ tentativa de desenvolver políticas educacionais no Brasil que atendam às necessidades reais dos estudantes, principalmente das escolas públicas, a escola de ensino integral de tempo integral surgiu como uma forma de solucionar problemas de aprendizagem, reprovação e evasão. Foram criados programas e centros de tempo integral: PROFICs (Programa de Formação Integral da Criança) em São Paulo, os CIEPs (Centro Integrado de Educação Pública) no Rio de Janeiro ou, mesmo em Curitiba, com os CEIs (Centro de Educação Integral); e o Programa Mais Educação, que em sua grande maioria foram mal entendidos e concebidos como assistencialismo pedagógico (FANK; HUTNER, 2013).

Alguns desses programas de educação integral utilizaram-se de trabalhos de parcerias com empresas privadas, terceirização de serviços de profissionais contratados para atividades pontuais e desarticuladas do currículo escolar, mobilização comunitária ou incentivo de trabalhos ao voluntariado. Essas ações desviam-se totalmente do objetivo da escola de ensino integral de tempo integral que oferece uma formação integral do estudante, não só das suas capacidades cognitivas, mas do desenvolvimento socioemocional. 
No Estado de Mato Grosso do Sul, o ensino integral foi implantado por meio da Lei ${ }^{\circ}$ 4.973, de 29 de dezembro de 2016, com a criação do ensino ampliado denominado "Escola da Autoria" (MATO GROSSO DO SUL, 2016). Tal política tem por objetivos gerais a ampliação da jornada escolar, o desenvolvimento de políticas direcionadas à melhoria da qualidade do ensino e à formação integral e integrada do estudante. Em virtude dessa lei o Plano Estadual de Educação (PEE- 2015) estabeleceu como Meta seis deveres de implantação e implementação gradativa da educação em tempo integral em, no mínimo, 65\% das escolas públicas, de forma a atender, pelo menos, $25 \%$ dos(as) estudantes da educação básica.

No que diz respeito ao cenário nacional, a Resolução CNE/CEB n. ${ }^{\circ}$ 7/2010/13, no art. 36, regulamentou que o ensino integral em tempo integral possui especificidades tanto na carga horária diária como anual: "Considera-se como de período integral a jornada escolar que se organiza em 7 (sete) horas diárias, no mínimo, perfazendo uma carga horária anual de, pelo menos, 1.400 (mil e quatrocentas) horas (BRASIL, 2013).

De acordo com a Resolução citada a organização de uma escola com tempo integral não diz respeito somente à jornada estendida, mas também à possibilidade de oferecer múltiplas oportunidades de aprendizagem aos estudantes da educação básica, com acesso à cultura, à arte, ao esporte, à ciência e à tecnologia, por intermédio de atividades educativas, sempre alinhadas à proposta pedagógica da escola nos diversos contextos escolares.

Quando trata da educação integral no campo das políticas educacionais, a meta do PNE - Plano Nacional de Educação Lei n ${ }^{\circ}$ 13005/2014 (BRASIL, 2014) é alcançar 50\% das escolas brasileiras até 2024. Destarte alguns planos deverão ser colocados em ação como: a reelaboração dos Projetos Políticos Pedagógicos (PPP), dos regimentos escolares e dos currículos de forma coletiva; maiores investimentos financeiros; formação continuada dos profissionais da educação; dedicação exclusiva em período integral dos docentes na escola; trabalho em articulação e parceria com instituições locais, para oferta de atividades artísticas, culturais, esportivas, entre outras; utilização de outros espaços públicos ociosos da comunidade; disponibilização de materiais pedagógicos e midiáticos; acompanhamento e avaliação permanente, orientação, monitoramento e autoavaliação para replanejamentos futuros.

Essas questões emanadas da meta 6 do PNE (BRASIL, 2014) precisam ser compreendidas e assumidas por toda a comunidade escolar, visto que cada seguimento desempenha sua função de forma proativa compreendendo todos os processos e dimensões que podem melhorar o processo ensino/aprendizagem. As estratégias traçadas para alcançar a meta 6 baseiam-se em atividades multidisciplinares, pois envolvem diferentes agentes e instituições sociais. 
Cada estratégia proposta na política educacional do PNE (BRASIL, 2014) precisa de planos de ação bem elaborados e executados para alcançar o foco principal: a aprendizagem e o desenvolvimento do estudante. A escola integral em tempo integral passa pela necessidade de emancipar o sujeito escolar w que ele reflita sobre o seu papel social, para assim, transformar a sua realidade social.

No Estado de Mato Grosso do Sul, as políticas de implantação de escolas de educação integral em período integral respeitam os preceitos da legislação nacional vigente e dialoga com a necessidade de um olhar educativo que contemple as necessidades formativas dos sujeitos escolares sul-mato-grossenses.

As 12 primeiras escolas de tempo integral no Estado de Mato Grosso do Sul foram implantadas em 2017. Em 2019 o número aumentou para 29 e, nesse mesmo ano, foi anunciada a ampliação da rede para 42 unidades divididas em 22 municípios. Para o Portal da Transparência, a implantação de escolas de tempo integral no Estado de 2019 para 2020 representou um aumento de $51 \%$, se comparada ao avanço do ano anterior. De acordo com o Portal, o número de alunos atendidos em 2019 foi de 5,5 mil, o que representa uma média de 40\% de aumento no número de matrículas (MATO GROSSO DO SUL, 2020).

De acordo com a proposta da Rede Estadual de Educação Básica de Ensino de Mato Grosso do Sul, o método de ensino e aprendizado nas Escolas de Autoria requerem que os alunos recebam além das disciplinas da BNCC Base Nacional Comum Curricular (BRASIL, 2017), disciplinas que atuem na formação individual a qual é denominada "Projeto de Vida" e direciona o aluno ao amadurecimento em diversas dimensões, incluindo o que ele pretende fazer na faculdade e, nos componentes curriculares eletivos, ele opta pelos que possui maior interesse, fazendo assim as suas escolhas (MATO GROSSO DO SUL, 2016).

A perspectiva da escola de ensino Integral de tempo integral é de grande interesse governamental e as políticas públicas do Estado tem contribuído para a ampliação dessa modalidade, tanto em respeito ao Plano Nacional de Educação, quanto à políticas educacionais locais, por entender que no cenário atual, a escola pode ser uma grande impulsionadora de uma sociedade mais ética, justa e consciente dos seus direitos e deveres, embora, há problemas de ordem geral que muitas vezes impedem a efetivação da política educacional devido à falta compreensão dos envolvidos nesse processo, por isso é preciso investir na formação continuada e em serviço, para que ocorra a integração coletiva de todos os seguimentos da escola (NÓVOA, 2007). 


\section{A escola integral em período integral no Estado de Mato Grosso do Sul: a Escola de Autoria}

Escola da Autoria pressupõe a construção de possibilidades, a produção do conhecimento por meio de um processo de totalidade, que envolve o sujeito em todas as suas possibilidades e potencialidades. No entanto, é necessário que o espaço educativo crie possibilidades para a reconstrução social com respeito às individualidades e às especificidades, propiciando ações na busca do bem comum e do respeito à democracia.

Em se tratando de uma escola que coloca o sujeito como autor da construção do conhecimento, como valorizar o saber e construir a capacidade de pesquisa e aprendizagem entre alunos que se envergonham de perguntar? Que atitude educativa deve tomar o professor quando, diante da pergunta de um colega, os demais o ridicularizam? Como resgatar a valorização da capacidade de perguntar, de indagar? Neste sentido, a escola deve desenvolver sujeitos para agir na sociedade de forma plena, pois estamos vivendo em uma sociedade em constante transformação e atividades rotineiras e repetitivas não é um meio de promover a sua autonomia. Essas atividades não conduzem um pensamento crítico, uma vez que pouco se exploram o seu ponto de vista as suas dúvidas; desse modo não cria as oportunidades de aprender, o professor não participa como mediador do conhecimento, querendo apenas o resultado final, não a sua construção (NININ, 2008).

Dessa forma, a autoria é a metodologia de aprendizagem adotada nas instituições de ensino em tempo integral do Estado de Mato Grosso do Sul onde o professor é o mediador e o estudante o protagonista que faz a parceria com o docente - isso Nóvoa (2007) presume de aprendizagem colaborativa. Ao observarmos a descrição dos componentes curriculares nos documentos que norteiam a modalidade de ensino, notamos grandes diferenças entre o currículo e a matriz curricular. Uma jornada de 9 tempos escolares (aulas) de 50 minutos com total de 200 dia letivos, que são bem definidos em atividades integradoras, Base Nacional Comum Curricular e a Parte Diversificada, porém, ainda buscando meios de se definir enquanto proposta pedagógica.

A matriz curricular do ensino fundamental também ampliou, principalmente, as disciplinas de Língua Portuguesa e Matemática em todos os anos escolares e, incluiu outras disciplinas cuja escolha parte da necessidade do estudante, pois são componentes eletivos.

As matrizes apresentam a organização dos tempos de aprendizagem, tanto da Base Nacional Comum Curricular e da Parte diversificada, quanto das Atividades Integradoras. Todas elas precisam ser compreendidas e aplicadas de forma efetiva para compor o ensino integral. As atividades Integradoras são: Estudo Orientado, Atividades Eletivas I e II Práticas 
de Convivência e de Socialização sempre que possível, devem ser planejadas em conjunto pelos professores dos componentes curriculares da Base Nacional Comum e contemplar várias formas de trabalho com os conteúdos, atendendo aos diversos saberes dos estudantes (MATO GROSSO DO SUL, 2016).

Ao que diz respeito ao Estudo Orientado, compete (4 h/a semanais por turma) nesse período e os estudantes articulam-se com o professor para o desenvolvimento de atividades que fortalecerão a compreensão dos conteúdos dos componentes curriculares da Base Nacional Comum Curricular, por meio de atividades que integrem os conhecimentos, como problematizações, roteiro de estudos, tarefas de aprendizagem e outros procedimentos metodológicos que promovam o protagonismo dos estudantes, a autoria e a pesquisa. As Práticas de Convivência e Socialização deverão acontecer nos horários de almoço com duração de 1 (uma) hora/aula e considerar os aspectos sociais, culturais e emocionais envolvidos nas relações humanas, objetivando o aprimoramento intra e interpessoal (MATO GROSSO DO SUL, 2016).

As atividades eletivas I e II precisam desenvolver práticas diferenciadas que promovam a socialização, autoconsciência, habilidades sociais como atenção. $\mathrm{O}$ projeto de vida que se consubstancia como componente curricular da parte diversificada procura estabelecer relações entre o passado e o presente na articulação do futuro, promovendo reflexão, diálogos, compartilhamento e objetivos a serem alcançados. São temas voltados para despertar sonhos e planos com o intuito de projetar a vida desse estudante, desenvolver as competências socioemocionais e atividades de autorreflexão conhecendo o perfil do estudante. "Quem sou eu e o que quero ser". Segundo o Referencial Curricular do Estado de Mato Grosso do Sul:

[...] a expressão "projeto de vida" também remonta ao desenvolvimento pleno da pessoa, visto que a educação integral deve proporcionar práticas pedagógicas que auxiliem na tomada de decisões, na resolução de problemas e em situações que vão além do planejamento $(2019$, p. 52)

O estudante nesse sentido tem um espaço de apoio para dedicar-se aos seus interesses e objetivos de vida, tempo de rememorar o que estudou e o docente tem o tempo para planejar o projeto de formação continuada, memória didática, mapeamento do perfil do aluno que poderá ser conduzido por indagações: Quais são os sonhos dos estudantes? O que eles sentem? Do que precisam para se desenvolver? Como melhorar sua qualidade de vida presente e futura? Que realidade esse estudante vive? Esse mapeamento precisa ser visualizado.

O currículo da escola de autoria no Estado de mato Grosso do Sul apresenta sugestões para traçar um perfil de estudante e desenvolver competências e habilidades necessárias ao 
ensino/aprendizagem. A escola deve promover sujeitos para agir na sociedade de forma plena, pois estamos vivendo em uma sociedade em constante transformação e atividades rotineiras e repetitivas não é um meio de promover a sua autonomia. Nesse contexto, a escola se transforma em um espaço essencial para assegurar que os educandos tenham garantida uma formação integral (YOUNG, 2007).

Nesse contexto de educação integral em tempo integral, a escola deve assumir o papel de articuladora das diversas experiências educativas que os alunos podem viver dentro e fora dela, a partir de uma intencionalidade clara que favoreça as aprendizagens importantes para o seu desenvolvimento integral.

\section{Considerações Finais}

O papel social que a educação desempenha na sociedade contemporânea é inegável. A escola atual é vislumbrada como um espaço de aprendizagem e transformação dos sujeitos que nela convivem diariamente. O conhecimento escolar é constituído tanto das relações sociais quando dos saberes acumulados ao longo da nossa existência.

Talvez, o grande desafio da escola integral de tempo integral seja compreender sua constituição, seu verdadeiro objetivo e as políticas educacionais que viabilizam seu funcionamento. O Currículo Integrado aliado à Proposta Pedagógica, a Matriz Curricular e o Referencial Curricular definem as atividades que serão oferecidas aos estudantes nos parecem ser o norte da proposta.

Ao analisarmos alguns dados referentes às primeiras escolas de tempo integral no Estado de Mato Grosso do Sul e o período histórico do qual elas pertencem, podemos notar que foram insuficientes para representar uma concepção política e pedagógica sobre a política nacional de escola integral. Houve grande equívoco em relação ao tempo estendido.

Em se tratando da escola integral de tempo integral, o tempo escolar não pode ser o tempo cronológico e o tempo físico não pode ser mitificado ou definido pela tradição escolar. Este tempo precisa estar de acordo com a proposta pedagógica da escola que pressupõe um currículo integrado às vivências do educando.

A educação integral que a Secretaria de Educação do Estado de Mato Grosso Sul preconiza está fundamentada na proposta de Educar pela Pesquisa, Protagonismo Juvenil, a Pedagogia da Presença, os quatro pilares da educação (aprender a conhecer, aprender a fazer, aprender a viver e aprender a ser), bem como a educação interdimensional e interdependente. A proposta precisa ser compreendida por toda a comunidade escolar, para que seja 
implementada e atenda às necessidades dos estudantes e a escola, não seja apenas um lugar assistencialista, onde crianças e jovens passem parte do dia - é necessário o desenvolvimento humano.

O Projeto Político Pedagógico da escola (PPP), precisa estar alinhado aos propósitos e fundamentos da Educação em Tempo Integral, denominado "Escola da Autoria”. Por isso além do debate sobre a constituição da escola e seu papel social, precisa de um amplo processo de formação continuada dos profissionais, para que a política pública em questão não se torne mais um projeto que não cumpriu o seu efeito - é preciso grandes investimentos tanto humanos, como financeiros.

$\mathrm{O}$ atual contexto educacional vislumbra a necessidade da ampliação dos tempos e espaços escolares, no entanto, necessita de concepções de educação que rompam com as fragilidades constatadas no Sistema Nacional de Educação Brasileiro e promova uma educação sólida e resistente, para enfrentar as demandas que a escola vem recebendo e transformar o sujeito, o que consequentemente, melhora a sua atuação social.

\section{REFERÊNCIAS}

ALVES, Joana D'arc Moreira. Escola de tempo integral: uma reflexão sobre suas contribuições e seus desafios, considerando a diversidade e a inclusão. Itinerarius Reflectionis: revista eletrônica do curso de Pedagogia, Jataí-UFG, v. 2, n. 11, 2011.

ANK, Elisane; HUTNER, Mary Lane. Escola em tempo integral e a educação integral: algumas reflexões de contexto e de concepção. In: Congresso Nacional de Educação EDUCERE, 04., 2013. Curitiba, Anais [...]. Curitiba: PUC/PR, 23 a 26/09/2013.

BRASIL. Lei n. 4.024, de 20 de dezembro de 1961. Fixa as diretrizes e bases da educação nacional. Brasília, DF: Câmara, 1961.

MAGALHÃES, Olinda Rodrigues. Educação e desafios perspectivas. Revista Científica Multidisciplinar Núcleo do Conhecimento, Ano 03, Ed. 09, v. 03, p. 65-73, set. 2018. ISSN:2448-0959.

MATO GROSSO DO SUL. Ampliação das escolas de tempo integral no Mato Grosso do Sul em 2018. Disponível em: www.ms.gov.br > governo-amplia-escolas-de-autoria-e-mais12-colegios-v...P. Acesso em: 20 jan. 2020.

MATO GROSSO DO SUL. Lei n. 5.306, de 21 de dezembro de 2018. Altera o caput e acrescenta o $\S 5^{\circ}$ ao art. $3^{\circ}$-A da Lei n. 4.973, de 29 de dezembro de 2016 , que cria o Programa de Educação em Tempo Integral, denominado "Escola da Autoria". Diário Oficial do Estado, Campo Grande, MS, 26 dez. 2018. Disponível em: https://www.spdo.ms.gov.br/diariodoe/Index/Download/DO9807_26_12_2018. Acesso em: 10 jan. 2020. 
MATO GROSSO DO SUL. Currículo de referência de Mato Grosso do Sul: educação infantil e ensino fundamental. Campo Grande: SED, 2019. Disponível em: https://www.sed.ms.gov.br/institucional/portal-do-servidor/F. Acesso em: 10 jan. 2020.

MATO GROSSO DO SUL. Resolução/SED n. 3.557, de 18 de janeiro de 2019. Diário Oficial do Estado, Campo Grande, MS, 21 jan. 2019. Disponível em: https://www.spdo.ms.gov.br/diariodoe/Index/Download/DO9825_21_01_2019. Acesso em: 15 dez. 2019.

MATO GROSSO DO SUL. Governo do Estado amplia oferta do Ensino Médio em Tempo Integral e contará com 42 escolas em 2020. Portal do Governo de Mato Grosso do Sul, 02 jan. 2020. Disponível em: http://www.ms.gov.br/governo-do-estado-amplia-oferta-do-ensinomedio-em-tempo-integral-e-contara-com-42-escolas-em-2020/. Acesso em: 25 mar. 2020.

MAURÍCIO, Lúcia Velloso. Escritos, representações e pressupostos da escola pública de horário integral. In: MAURÍCIO, Lúcia Velloso (Org.). Educação integral e tempo integral. Brasília: INEP/MEC, p. 15-31, 2009.

MOLL, Jaqueline. Histórias de vida, histórias de escola: elementos para uma pedagogia da cidade. Petrópolis: Vozes, 2000.

MOSÉ, Viviane. A escola e os desafios contemporâneos. Rio de Janeiro: Civilização Brasileira, 2013.

NININ, Maria Otilia Guimarães. Pesquisa na escola: que espaço é esse? O conteúdo ou do pensamento crítico. Educação em Revista, Belo Horizonte, n. 48, p. 16-35, dez. 2008. Disponível em: http://www.scielo.br/pdf/edur/n48/a02n48.pdf. Acesso em: 15 dez. de 2019.

NÓVOA, António. Desafios do trabalho do professor no mundo contemporâneo. São Paulo: Sinpro, 2007. Disponível em:

http://www.sinprosp.org.br/arquivos/novoa/livreto_novoa.pdf. Acesso em: 28 jan. 2020.

YOUNG, Michael. Para que servem as escolas? Revista Educação e Sociedade, Campinas, v. 28, n. 101, p. 1287-1302, set./dez. 2007. Disponível em:

http://www.scielo.br/pdf/es/v28n101/a0228101.pdf. Acesso em: 16 mar. 2020.

\section{Como referenciar este artigo}

PEIXOTO, Reginaldo; MAGALHÃES, Olinda Rodrigues. Escola integral de tempo integral no Estado de Mato Grosso do Sul: reflexões sobre sua constituição e os desafios da política educacional. Revista on line de Política e Gestão Educacional, Araraquara, v. 24, n. 2, p. 390-403, maio/ago. 2020. E-ISSN:1519-9029. DOI: https://doi.org/10.22633/rpge.v24i2.13492

Submetido em: 20/01/2020

Revisões requeridas: 19/02/2020

Aprovado em: 02/04/2020

Publicado em: 09/04/2020 